\title{
SISTEM CERDAS PEMBERI PAKAN IKAN SECARA OTOMATIS
}

\author{
Hayatunnufus $\left.{ }^{*}, 1\right)$, Debby Alita ${ }^{2)}$ \\ 1) Program Studi Ilmu Komputer, Fakultas Ilmu Komputer dan Teknologi Informasi, Universitas Sumatera Utara \\ Jl. Alumni No.2, Padang Bulan, Kec. Medan Baru, Kota Medan, Sumatera Utara 20155 \\ 2) Program Studi Informatika, Fakultas Teknik dan Ilmu Komputer, Universitas Teknokrat Indonesia \\ Jl. ZA. Pagar Alam No.9 -11, Labuhan Ratu, Bandar Lampung, Indonesia 35132 \\ Email: 'hayatunnufus@usu.ac.id
}

\begin{abstract}
The ornamental fish feeder at the aquarium automatically is an intelligent system that aims to facilitate the feeding, so that when the fish keeper has a fairly busy schedule and feels difficult when leaving home for a long time, the fish will stay awake in the process of giving the feed. The system designed consists of four parts, namely: power supply, minimum system, mechanical circuit and program. The workings of this tool are by regulating the feeding of the Fish Feeding Device which is set by the microcontroller using the RTC (Real Time Clock), arduino as a process, DC motor (Direct Current) as the output condition and LCD (Liquid Crystal Display) as the user interface and monitoring. The addition of Ultrasonic sensors to monitor the state of the feed in the container. Based on the test results and for the work of "Ornamental Fish Feeder Equipment in the Aquarium Automatically" has shown results in accordance with the plan that the tool can provide fish feed automatically at a predetermined time.
\end{abstract}

Keywords: $D C$, Intellegence System, RTC, LCD

\section{Abstrak}

Alat Pemberi Pakan Ikan Hias Di Aquarium Secara Otomatis merupakan sistem cerdas yang bertujuan untuk mempermudah dalam pemberian pakannya, sehingga ketika pemelihara ikan memiliki kesibukan yang cukup padat dan merasa kesulitan ketika akan pergi meninggalkan rumah dalam waktu yang cukup lama, maka ikan akan tetap terjaga dalam proses pemberian pakannya. Sistem yang dirancang terdiri dari empat bagian yaitu: catu daya, sistem minimum, rangkaian mekanika dan program. Cara kerja alat ini yaitu dengan mengatur pemberian makanan pada Alat Pemberi Pakan Ikan yang diatur oleh mikrokontroler menggunakan parameter waktu RTC (Real Time Clock), arduino sebagai proses, motor DC (Direct Current) sebagai kondisi output dan LCD (Liquid Crystal Display) sebagai user interface dan monitoring. Penambahan sensor Ultrasonik untuk memantau keadaan pakan dalam penampung. Berdasarkan hasil pengujian dan untuk kerja dari "Alat Pemberi Pakan Ikan Hias Di Aquarium Secara Otomatis” telah menunjukkan hasil yang sesuai dengan perencanaan yaitu alat dapat memberikan pakan ikan secara otomatis pada waktu yang telah ditentukan.

Kata Kunci: DC, Sistem Cerdas, RTC, LCD

\section{Pendahuluan}

Perkembangan teknologi di bidang elektronika semakin berkembang pesat dan berpengaruh terhadap pembuatan alat-alat canggih[1][2]. Hal tersebut dapat menciptakan alat yang dapat bekerja secara otomatis, cepat, tepat, dan memiliki ketelitian tinggi, sehingga dapat mempermudah pekerjaan yang dilakukan oleh manusia menjadi lebih praktis[3]. Perkembangan teknologi tersebut mendorong kehidupan manusia untuk hal-hal yang otomatis sehingga dapat mempermudah pekerjaan manusia dengan memanfaatkan kemajuan teknologi [4][5]. Otomatisasi dalam semua sektor yang tidak dapat dihindari, sehingga pengguna yang awalnya manual bergeser ke otomatisasi .

Dalam kehidupan sehari-hari di kota maupun di desa terdapat banyak orang yang memelihara ikan hias di dalam aquarium. Memelihara ikan adalah suatu hobi yang banyak diminati oleh masyarakat dari dahulu hingga sekarang. Karena kemudahannya dalam pemeliharaan dan perawatannya yang membuat kebanyakan orang ingin memeliharanya. Ikan yang dipelihara dalam aquarium harus diperhatikan waktu pemberian pakannya sehingga ikan tersebut membutuhkan jadwal untuk pemberian pakan yang teratur[6][7][8]. Namun, untuk masyarakat yang memiliki tingkat kesibukan yang cukup padat, maka akan merasakan kesulitan ketika mereka akan pergi meninggalkan rumah dalam waktu yang cukup lama. Karena pemenuhan kebutuhan ikan terutama pada pemberian pakan ikan akan terganggu [9][10].

Pada saat ini dalam pemberian pakan meminta bantuan orang lain untuk memberikan pakan. Berdasarkan hal tersebut dirancanglah sebuah alat yang dapat memberi pakan ikan di aquarium secara otomatis pada waktu-waktu yang telah ditentukan, dengan alat ini maka diharapkan dapat menjadi alternatif solusi bagi masyarakat yang hobi memelihara ikan tanpa merasa khawatir ketika meninggalkan rumah dalam waktu yang lama. 


\section{Analisis dan Perancangan}

Perancangan memerlukan suatu ketelitian, keuletan dan ketepatan karena perancangan awal akan menentukan akhir dari suatu perancangan dalam pross pembuatan alat [11][12]. Jika perancangan awal salah maka hasil akhirnya akan salah. Proses perancangan sangat diperlukan dalam pross pembuatan alat, hususnya perancangan alat elektronika.

\subsection{Diagram Blok}

Pada gambar diagram blok di bawah ini menjelaskan tentang blok-blok alat secara keseluruhan mulai dari input, proses, hingga output dalam diagram blok ini hanya terdapat hubungan jalur antara blok-blok saja, tetapi tiap masing-masing blok terdapat komponen utama dan komponen pendukung. Pada gambar 1 berikut ini adalah gambar diagram blok dari mikrokontroler alat yang dirancang.



Gambar 1. Blok Diagram Kerja Alat Pemberi Pakan Ikan Hias di Aquarium

1.2 Perancangan Sensor Ultrasonic HC-SR04

Sensor ultrasonic HC-SR04 digunakan sebagai pendeteksi keadaan pakan dalam bak penampung pakan ikan, dengan kata lain sensor ultrasonik berfungsi sebagai saklar otomatis.



Gambar 2. Rangakaian Sensor Ultrasonic HCSR04
1.3 Perancangan Rangkaian LCD (Liquid Crystal Display)

LCD berfungsi untuk menampilkan status yang sedang terjadi pada alat[13][14]. Dalam proyek ini LCD berfungsi menampilkan waktu, dan informasi pakan habis. Berikut adalah rangkaian LCD 16x2 dengan Modul I2C pada rangkaian mikrokontroller arduino.

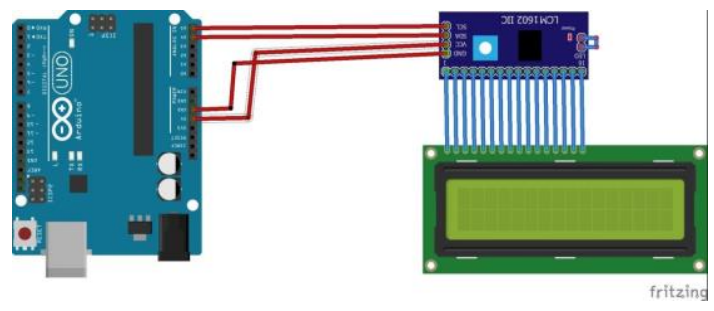

Gambar 3. Rangakaian LCD dengan module 12C

1.4 Perancangan Motor DC

Pada alat ini motor DC berfungsi sebagai pengerak mekanik [15] yang akan memberikan pakan ikan, ketika motor DC berputar maka pakan akan ikut keluar. Rangakaiannya dapat dilihat pada gambar berikut:



Gambar 4. Rangakaian Motor DC

1.5 Perancangan Real Time Clock DS 3231

Pada alat ini RTC dihubungkan dengan pin analog A4 dan pin sel RTC dihubungkan dengan pin analog A5 pada arduino uno. Untuk lebih jelas hubungan rangkaiannya dapat dilihat pada gambar berikut :

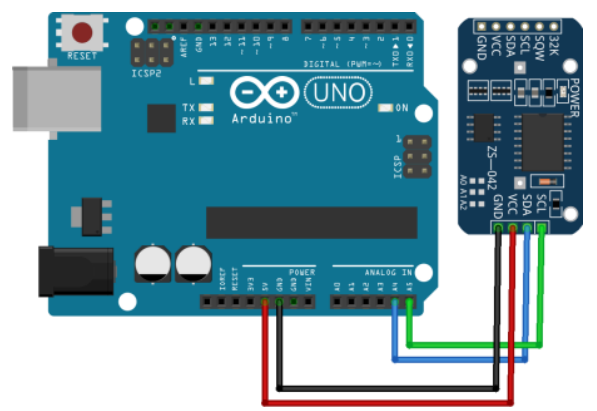

Gambar 5. Rangakaian RTC (Real Time Clock) DS 3231 
1.6 Perancangan Buzzer

Pada alat ini buzzer digunakan sebagai pemberi sinyal atau notif berupa suara apabila pakan pada wadah penampung pakan ikan kurang dari $20 \%$.



Gambar 6. Rangkaian Buzzer

1.7 Rangkaian Perangkat Keras Secara Keseluruhan

Terdapat 14 port output yaitu port 1 (RX), 2 (TX), 3 , $4,5,6,7,8,9,10,11,12,13$, dan 6 port analog input yaitu A0, A1, A2, A3, A4, dan A5. Pemasangan komponen pada mikrokontroler dapat dilihat pada gambar berikut ini:



Gambar 7. Rangkaian Perangkat Keras Secara Keseluruhan

\subsection{Alat dan Bahan}

Dalam pembuatan alat tugas akhir ini memerlukan beberapa komponen dan bahan. Komponen dan bahan yang digunakan dalam pembuatan alat ini adalah:

Tabel 1. Komponen yang digunakan

\begin{tabular}{|c|c|c|}
\hline No & Alat dan Bahan & Jumlah \\
\hline 1 & Arduino Uno & 1 \\
\hline 2 & $\begin{array}{l}\text { Sensor RTC DS3231 (real } \\
\text { time clock) }\end{array}$ & 1 \\
\hline 3 & $\begin{array}{l}\text { Sensor Ultrasonic HC- } \\
\text { SR04 }\end{array}$ & 1 \\
\hline 4 & LCD $16 \times 2$ & 1 \\
\hline 5 & Module I2CLCD & 1 \\
\hline 6 & Motor DC & 1 \\
\hline 7 & Kabel tis & Secukupnya \\
\hline 8 & Kaleng Milo 240ml & 1 \\
\hline 9 & Kabel jumper & Secukupnya \\
\hline 10 & Black box & 1 \\
\hline 11 & Double tip & 1 \\
\hline 12 & Relay & 1 \\
\hline
\end{tabular}

\section{Hasil dan Pembahasan}

Tahapan penerapan sebuah program dan mekanika dalam pembangunan sistem. Implementasi dibuat berdasarkan hasil suatu analisis serta desain arsitektur yang terinci terhadap suatu sistem yang sedang berjalan. Sistem pemberi pakan ikan otomatis ini terdiri dari 1 buah motor DC, RTC(Real Time Clock), LCD (Liquid Crystal Display), dan 1 buah mikrokontroler arduino uno. RTC (Real Time Clock) berfungsi sebagai waktu pada mikrokontroler arduino, motor DC 12-N20 berfungsi sebagai pengerak untuk pakan ikan, LCD(Liquid Crystal Display) berfungsi sebagai penampil waktu dan mikrokontroler arduino sebagai otak dan pemroses keseluruhan komponen sistem.

2.1 Pemasangan alat pemberi pakan pada aquarium Alat pemberi pakan ikan hias ini di letakan pada bagian samping aquarium supaya keindahan ikan didalam aquarium tetap terlihat. Berikut ini adalah tampilan dari pemasangan alat pemberi pakan ikan hias pada sebuah aquarium.

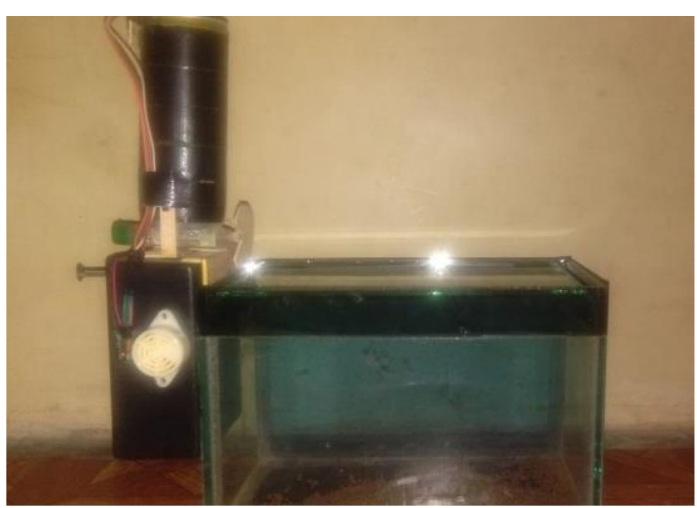

Gambar 8. Pemasangan Alat Pemberi Pakan Pada Aquarium Tampak Depan

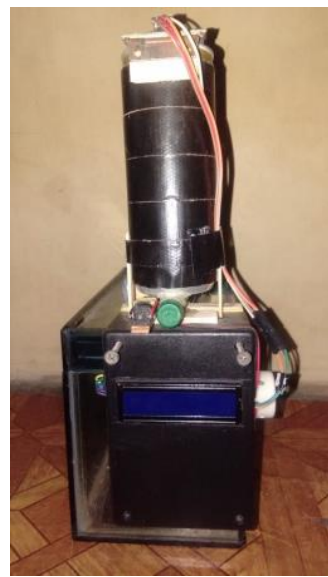

Gambar 9. Pemasangan Alat Pemberi Pakan Pada Aquarium Tampak Samping 


\subsection{Pengujian Catu Daya}

Pengujian ini dilakukan untuk mengetahui apakah semua komponen yang terhubung dapat menerima sumber tegangan secara baik dan menghindari perkabelan yang buruk atau terputus sehingga tidak ada salah satu komponen yang tidak menyala akibat tidak terpasok sumber tegangannya. Karna semua komponen mengambil daya dari mikrokontroler maka pengujian catudaya cukup dengan menghubungkan mikrokontroler pada sumber tegangan seperti adaptor, powerbank, ataupun leptop. Disini penulis menggunakan laptop

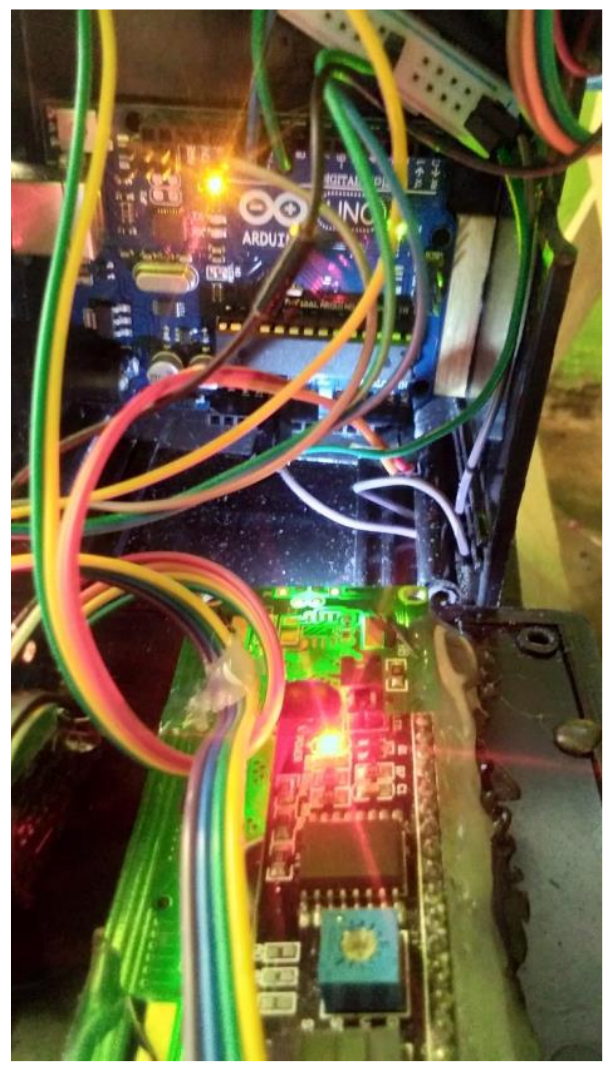

Gambar 10. Pengujian Catu Daya Pada Alat

Dapat dilihat bahwa sistem hidup, berarti bahwa catu daya berfungsi pada alat.

\subsection{Pengujian Mikrokontroler}

Pengujian selanjutnya dilakukan pada mikrokontroler Arduino Uno yang mana bagian ini merupakan pusat pengolahan data pada sistem penjadwalan ini. Pengujian yang akan dilakukan ini merupakan pengujian dengan memprogram mikrokontroler arduino dan mengukur pin output menggunakan multimeter. Hasil pengujian sebagai berikut:
Tabel 2. Hasil Pengujian Output Mikrokontroler Arduino Uno

\begin{tabular}{lcc}
\hline $\begin{array}{c}\text { Titik } \\
\text { Pengukuran }\end{array}$ & $\begin{array}{c}\text { Logika } \\
\text { Program }\end{array}$ & $\begin{array}{c}\text { Tegangan } \\
\text { Terbaca }\end{array}$ \\
\hline PIN 1 & 1 & $5 \mathrm{v}$ \\
PIN 2 & 0 & 0 \\
\hline
\end{tabular}

Setelah mengirim program kedalam arduino maka diukurlah tegangan pada pin 1 dan pin 2 jika dilihat pada tabel 2, pin 1 yang diberi logika $H I G H$ memiliki tegangan output sebesar $5 \mathrm{Vdc}$ sedangkan pin 2 yang diberi logika LOW memiliki tegangan output $0 \mathrm{Vdc}$.

\subsection{Pengujian Motor DC 12-N20}

Pengujian yang dilakukan berikutnya adalah pengujian Motor DC 12-N20, karena sebagai penggerak mekanik agar pakan ikan dapat keluar dari wadah penampungan maka motor DC 12-N20 harus dilakukan pengujian agar pakan ikan dapat keluar, pengujian dilakukan dengan cara mengaktifkan penjadwalan dengan waktu yang bukan sebenarnya dengan selisih setiap waktu 5 menit pada program yang di download, hasil dari pengujian bisa dilihat pada tabel berikut :

Tabel 3. Hasil Pengujian Motor DC 12-N20

\begin{tabular}{cccc}
\hline No & $\begin{array}{c}\text { Jam } \\
\text { Penjadwalan }\end{array}$ & $\begin{array}{c}\text { Jam } \\
\text { makan }\end{array}$ & Motor DC \\
\hline 1 & 15.08 & Pagi & Berputar \\
2 & 15.13 & Sore & Berputar \\
3 & 15.18 & Pagi & Berputar \\
4 & 15.23 & Sore & Berputar \\
5 & 15.28 & Pagi & Berputar \\
6 & 15.33 & Sore & Berputar \\
\hline
\end{tabular}

Dari hasil pengujian pada tabel 3 diambil contoh 6 kali penjadwalan dengan selisih tiap waktunya adalah 5 menit dan mensimulasikan jam makan pagi, dan sore pada ikan. Motor DC 12-N20 pun berfungsi dengan baik dan sesuai dengan apa yang diharapkan pada saat sistem bekerja.

\subsection{Pengujian Sensor Ultrasonik}

Pengujian Sensor Ultrasonik dimaksudkan untuk mengetahui seberapa tepat dan akurat sensor HC-SR04 ini dalam menentukan jarak pakan yang ada didalam penampung, sehingga mampu menilai tingkat ketepatan sistem saat membaca jarak dan mengirimkan nilai pembacaannya ke mikrokontroler, cara yang dilakukan adalah melakukan pengukuran sensor jarak dengan penggaris dan penghalang dengan jarak $20 \mathrm{~cm}$ saja. Hasil pengukuran dapat diperlihatkan pada tabel 4 
Tabel 4 Hasil Pengujian Sensor Ultrasonik

\begin{tabular}{ccc}
\hline No & $\begin{array}{c}\text { Data Sensor } \\
(\mathrm{cm})\end{array}$ & $\begin{array}{c}\text { Jarak } \\
\text { Sebenarnya } \\
(\mathrm{cm})\end{array}$ \\
\hline 1 & 2 & 2 \\
2 & 2 & 3 \\
3 & 3 & 3 \\
4 & 3 & 4 \\
5 & 4 & 4 \\
6 & 4 & 5 \\
7 & 5 & 5 \\
8 & 5 & 6 \\
9 & 6 & 6 \\
10 & 6 & 7 \\
\hline
\end{tabular}

Dari data yang telah diuji maka dapat diketahui bahwa selisih dari sensor jarak dengan jarak sebenarnya tidak terpaut jauh atau masih bisa dikatakan dalam toleransi kesalahan, sehingga sensor jarak berfungsi dengan baik pada sistem ini.

\subsection{Pengujian LCD}

Pengujian pada LCD dimaksudkan agar dapat mengetahui bahwa LCD mampu menampilkan informasi dengan baik dan sesuai dengan apa yang diharapkan pada sistem saat menginputkan jadwal pemberian pakan pada ikan. Pengujian dilakukan dengan cara menampilkan semua yang berhubungan dengan tampilan layar pada LCD berikut gambar untuk memperlihatkan hasil pengujian LCD pada saat digunakan,

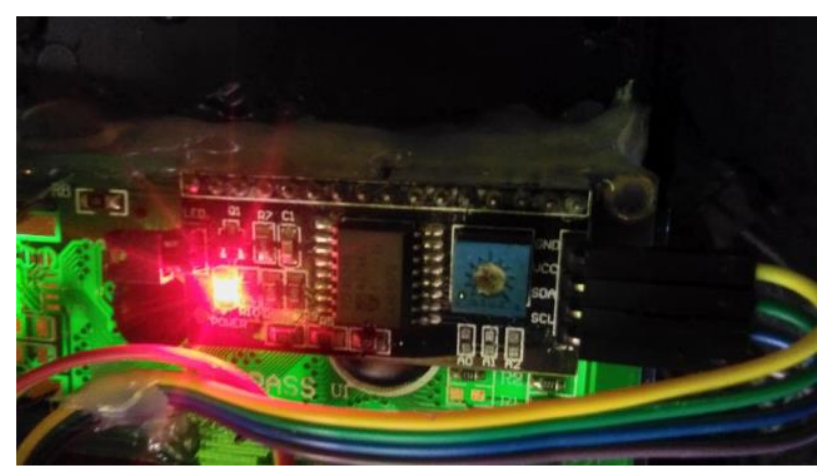

Gambar 11. Tampilan I2C Menyala Saat Mendapat Tegangan

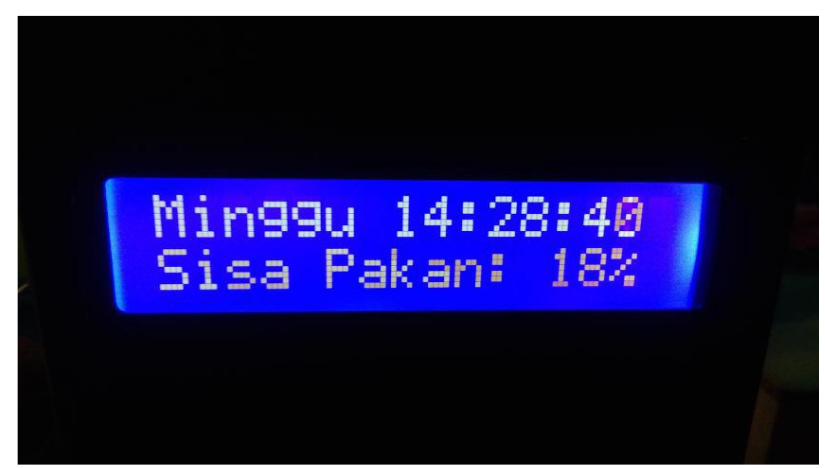

Gambar 12. tampilan pada layar LCD ketika sistem pada alat dalam

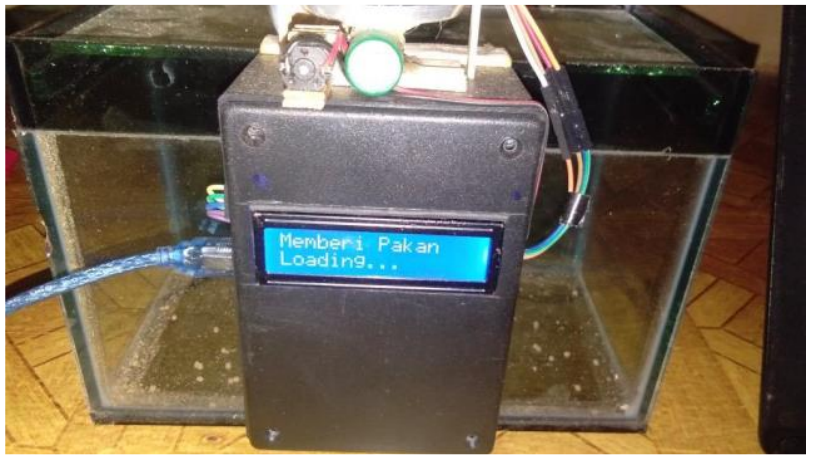

Gambar 13. tampilan pada layar LCD ketika sistem memberi pakan

\subsection{Pengujian RTC}

Pengujian RTC bertujuan untuk mngetahui apakah RTC mampu menjadi pewaktu seperti jam digital (handphone). Pada pengujian kali ini dilakukan perbandingan jam makan pagi dan jam makan sore yang di setting pada program untuk jam RTC dengan jam digital (handphone). Cara pengujian dilakukan dengan mengganti waktu pemberian pakan ikan, dengan selisih 5 menit disetiap waktunya, hasil pengujian dapat dilihat pada tabel 5

Tabel 5. Hasil Pengamatan Jam RTC Dan Jam Digital (handphone)

\begin{tabular}{cccll}
\hline NO & $\begin{array}{c}\text { Jam } \\
\text { Handp } \\
\text { hone }\end{array}$ & $\begin{array}{c}\text { Jam } \\
\text { Settingan } \\
\text { RTC }\end{array}$ & $\begin{array}{c}\text { Simulasi } \\
\text { Jam Makan }\end{array}$ & Error \\
\hline 1 & 07.50 & 07.49 & Pagi & 1 menit \\
2 & 07.55 & 07.54 & Sore & 1 menit \\
3 & 08.00 & 07.59 & Pagi & 1 menit \\
4 & 08.05 & 08.04 & Sore & 1 menit \\
5 & 08.10 & 08.09 & Pagi & 1 menit \\
6 & 08.15 & 08.14 & Sore & 1 menit \\
7 & 08.20 & 08.19 & Pagi & 1 menit \\
8 & 12.02 & 12.01 & Sore & 1 menit \\
9 & 12.07 & 12.06 & Pagi & 1 menit \\
10 & 12.12 & 12.11 & Sore & 1 menit \\
& & & &
\end{tabular}

Dari tabel 5 diatas dapat dilihat bahwa pengujian alat yang dilakukan sebanyak 10 kali, pada percobaan jam RTC dengan jam digital (handphone) memiliki perbedaan waktu selama 1 menit dengan kata lain jam RTC lebih lambat 1 menit dibanding dengan jam digital (handphone). Itu terjadi karena saat mendownload program RTC membutuhkan waktu untuk proses sampai pada mikrokontroler untuk menginisialisasikan pin dan menyelesaikan prosesnya. Gambar dari RTC yang menyala saat diberikan tegangan adalah seperti pada Gambar 8 berikut: 


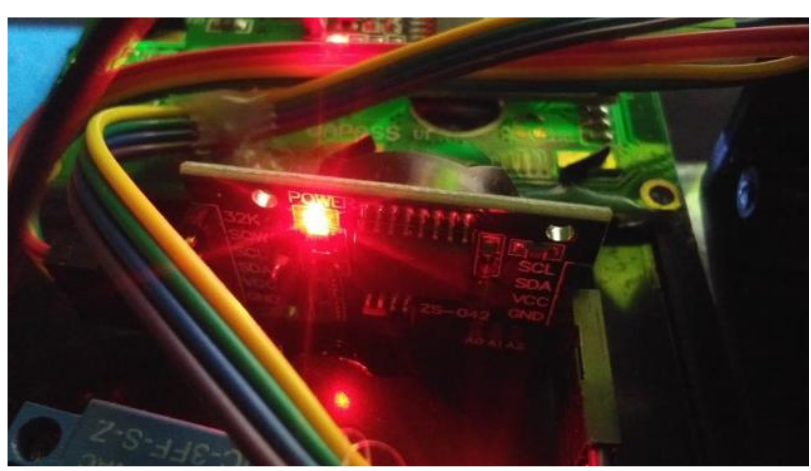

Gambar 14. Tampilan RTC Menyala Saat Mendapat Tegangan

\section{Kesimpulan}

Setelah dilakukan berbagai pengujian dan analisa terhadap rancang Alat Pemberi Pakan Ikan Hias di Aquarium Secara Otomatis, baik perangkat keras maupun perangkat lunak, dapat diambil beberapa kesimpulan sebagai berikut:

Sistem yang mempermudah pekerjaan manusia dalam memberi Pakan Ikan Hias di Akuarium Secara Otomatis Berbasis Mikrokontroler Arduino Uno memiliki empat bagian yaitu catu daya, sistem minimum, rangkaian motor DC 12-N20 dan program. Catu daya berfungsi sebagai penyuplai tegangan. Sistem minimum berupa rangkaian elektronik yang berfungsi sebagai pengolah data dengan mikrokontroler Arduino Uno sebagai pusat kendali. Rangkaian motor DC 12-N20 yang berfungsi untuk mengatur dalam pemberian pakan ikan. Dan program yang berfungsi untuk mengatur mikrokontroler sehingga alat dapat bekerja sesuai dengan fitur yang ditawarkan.

Untuk kerja dari Alat Pemberi Pakan Ikan Hias di Akuarium Secara Otomatis Berbasis Mikrokontroler Arduino Uno telah menunjukkan hasil yang sesuai dengan perencanaan yaitu alat dapat memberikan pakan ikan secara otomatis pada waktu yang telah ditentukan.

\section{Daftar Pustaka}

[1] S. Samsugi, Ardiansyah dan A. Suwantoro, "Pemanfaatan Peltier dan Heater Sebagai Alat Pengontrol Suhu Air Pada Bak Penetasan Telur Ikan Gurame," Conference on Information Technology, Information System and Electrical Engineering, pp. 295-299, 2016.
[2] K. Pindrayana, R.I. Borman, B. Prasetyo dan S. Samsugi, "Prototipe Pemandu Parkir Mobil Dengan Output Suara Manusia Mengunakan Mikrokontroler Arduino Uno," CIRCUIT: Jurnal Ilmiah Pendidikan Teknik Elektro, vol. 2, no. 2, 2018.

[3] Andrianto, Heri. 2008. Pemrograman Mikrokontroler AVR ATmega8535. Informatika. Bandung

[4] A. Nurkholis, A. Riyantomo dan M. Tafrikan, "Sistem pakar penyakit lambung menggunakan metode forward chaining," Majalah Ilmiah Momentum, vol. 13, no. 1, 2017.

[5] A. Nurkholis, dan I. S. Sitanggang, "Optimalisasi model prediksi kesesuaian lahan kelapa sawit menggunakan algoritme pohon keputusan spasial," Jurnal Teknologi dan Sistem Komputer, vol. 8, no. 3, pp. 192-200, Jul. 2020.

[6] S. Samsugi dan A. Burlian, "Sistem penjadwalan pompa air otomatis pada aquaponik menggunakan mikrokontrol Arduino UNO R3,". Prosiding Semnastek, vol. 1, no. 1, 2019.

[7] Arduino, 2016, Arduino Uno https://www.arduino.cc/en/Main/ArduinoBoardUno, diakses 11 Februari 2016.

[8] Artanto, Dian, S.T., M.Eng. Diklat kuliah Algoritma Pemrograman. Yogyakarta: FST-USD, 2007.

[9] Bachtiar, Y. 2003. Menghasilkan Pakan Alami Untuk Ikan Hias. Penerbit PT Agro Media Pustaka. Tangerang.

[10] Anonim. (2013). Elektronik Tutorial. Diakses 30 Januari 2013 pukul 21.45 WIB dari http://www.electronics-tutorials.ws/io/io 6.html

[11] D. Alita, S. Priyanta, and N. Rokhman, "Analysis of Emoticon and Sarcasm Effect on Sentiment Analysis of Indonesian Language on Twitter," J. Inf. Syst. Eng. Bus. Intell., vol. 5, no. 2, p. 100, 2019, doi: 10.20473/jisebi.5.2.100-109.

[12] Sulistiani, H., Miswanto, M., Alita, D., \& Dellia, P. (2020). Pemanfaatan Analisis Biaya Dan Manfaat Dalam Perhitungan Kelayakan Investasi Teknologi Informasi. Edutic-Scientific Journal of Informatics Education, 6(2).

[13] Budiharto, W., 2005, Perancangan Sistem dan Aplikasi Mikrokontroler, Elex Media Komputindo, Jakarta.

[14] Djarijah, A.S. 1996. Pakan Ikan Alami. Yogyakarta: Kanisius.

[15] I. K. Gunawan, A. Nurkholis dan A. Sucipto, "Sistem monitoring kelembaban gabah padi berbasis Arduino," Jurnal Teknik dan Sistem Komputer, vol. 1, no. 1, pp. 1-7, 2020. 